\title{
Time-kill kinetics and antibacterial activity of root extract of Adenodolichos paniculatus (Hua) Hutch \& Dalz (Fabaceae)
}

\author{
Friday I. KYAHAR ${ }^{1 *}$, Edith A. ONWULIRI ${ }^{1}$, Joseph O. EHINMIDU ${ }^{2}$ and Peters $O$. \\ OLADOSU $^{3}$
}

${ }^{I}$ Dept. of Pharmaceutical Microbiology and Biotechnology, Faculty of Pharmaceutical Sciences, University of Jos PMB 2084, Jos. Nigeria. ${ }^{2}$ Dept. of Pharmaceutics and Pharmaceutical Microbiology, Ahmadu Bello University Zaria. Nigeria. ${ }^{3}$ Dept. of Microbiology and Biotechnology, National Institute for Pharmaceutical Research and Development (NIPRD), Abuja. Nigeria.

Received 25 $5^{\text {th }}$ September 2020; Accepted $19^{\text {th }}$ April 2021

\begin{abstract}
Medicinal plants have been used in treatment of illness from time immemorial. Adenodolichos paniculatus is a medicinal plant used for traditional remedy of sore throat infections. This study therefore, evaluated the antibacterial activities of the root extracts and time-kill kinetics of the most potent extract. Five extracts, obtained by maceration using $n$-hexane, chloroform, ethyl acetate, methanol and water sequentially were evaluated for antibacterial activities and time-kill kinetics against Streptococcus pyogenes, Staphylococcus aureus, Pseudomonas aeruginosa and Escherichia coli. Chloroform root extract at $100 \mathrm{mg} / \mathrm{ml}$ was active against Streptococcus pyogenes, Staphylococcus aureus and Pseudomonas aeruginosa with zones of inhibition 25.00, 21.00 and $14.75 \mathrm{~mm}$ respectively but not against Escherichia coli. Minimum inhibitory concentrations were 1.56, 6.25 and $25.00 \mathrm{mg} / \mathrm{ml}$ respectively and the minimum bactericidal concentrations were 3.12, 12.50 and $50.00 \mathrm{mg} / \mathrm{ml}$. Complete elimination of S. pyogenes, $S$. aureus and $P$. aeruginosa was achieved at concentrations $1.56 \mathrm{mg} / \mathrm{ml}, 6.25 \mathrm{mg} / \mathrm{ml}$ and $25.00 \mathrm{mg} / \mathrm{ml}$ within 300, 720 and 960 minutes exposure respectively and at concentrations $3.12 \mathrm{mg} / \mathrm{ml}, 25.00 \mathrm{mg} / \mathrm{ml}$ and $50.00 \mathrm{mg} / \mathrm{ml}$ within 180,300 and 720 minutes exposure respectively. Chloroform root extract has the potential to be used as antibacterial agent and was better than the other solvent extract two-fold.
\end{abstract}

Keywords: Adenodolichos paniculatus; Antibacterial activity; Time-kill kinetics; Percentage reduction, Log reduction

\section{INTRODUCTION}

For decades, plants have been used by man as a natural source of therapy for the management of several illnesses and diseases. The use of plant compounds for pharmaceutical purposes has increased in Nigeria. The full integration of herbal medicine into the mainstream primary health care programs will require rigorous scientific study of both their therapeutic potentials as well as the assessment of safety [1]. Adenodolichos paniculatus (a shrub of $4-5 \mathrm{~m}$ high) found in the savanna, bush and jungle, from Guinea to Northern Nigeria, and across to Sudan [2] is also known by various ethnic names such as kpàrák (Berom), gargung (Mwaghavul), kilikainawa (Fulfulde) and waken wuta (Hausa) to mention but a few in Nigeria [3]. It is one of the important medicinal plants with widespread traditional uses in the

*Correspondence. E-mail: kyaharfriday@yahoo.com Tel: +234-8034531378.

ISSN 0189-8442

2021. Published by Faculty of Pharmaceutical Sciences, University of Jos, Nigeria. Under Creative Commons Attribution-Non-Commercial 4.0 International License. https://creativecommons.org/licenses/by-nc/4.0/ 
remedy and management of sore throat infections in Pushit community. Other folkloric uses include dressing of burns, dysentery, liver trouble, venereal diseases, dysentery, diarrhea, blennorrhoea and also used as a pain-killer $[4,6]$.

The scientific study of $A$. paniculatus has become imperative due to the alarming incidence of antibiotic resistance in bacteria of medical importance and the need to look for other sources of novel antibacterial agents particularly from medicinal plants, based on ethnopharmacological information [5]

The present study was therefore conducted to evaluate the antibacterial susceptibility of Streptococcus pyogenes, Staphylococcus aureus, Pseudomonas aeruginosa and Escherichia coli to $A$. paniculatus root extracts and to determine the rate of bactericidal activities within a given contact time of the most potent root extract.

\section{EXPERIMENTAL METHODS}

Materials. The roots of the plant Adenodolichos paniculatus were the specimen used for this study. The typed bacteria and clinical bacteria isolate used for the study included: Staphylococcus aureus-ATCC6538, Escherichia coli -ATCC43888 and Pseudomonas aeruginosa-ATCC9027 were obtained from central diagnostic lab-National Veterinary Research Institute (NVRI), Vom, Plateau state and Streptococcus pyogenesClinical isolate was obtained from Department of Microbiology and Bacteriology, National Institute for Pharmaceutical Research and Development-Diagnostic Centre, AbujaNigeria.

Collection, identification and extraction of plant materials. The plant specimens were harvested from the wild plant between October 2018 and March 2019. An herbalist was consulted as his experience was used to determine the best collection time and accurate location of the plant within the District of Pushit in Mangu LGA of Plateau State. The collected roots were cleaned, cut into bits, spread over a rack covered with cheesecloth and air-dried at room temperature $\left(25-28^{\circ} \mathrm{C}\right)$. The dried samples were pulverized with a mechanical grinder, sieved with $2.5 \mathrm{~mm}$ sieve and packed into clean, dried bottles and covered tightly. The bottles were labeled with the plant name and date of collection and stored at room temperature $\left(25-28^{\circ} \mathrm{C}\right)$ until ready for extraction. The plant was identified as Adenodolichos paniculatus on voucher number FHJ 205 and deposited at the Herbarium unit of Federal College of Forestry, Jos. The bioactive constituents of the plant were extracted with five solvent systems (nhexane, ethyl acetate, chloroform, methanol and water). This was to ensure that compounds with a wide range of polarity could be extracted. The serial maceration extraction technique was employed and successive extraction was carried out with solvents of increasing polarity from non-polar to more polar solvents [7].

One kilogram $(1 \mathrm{~kg})$ of the powdered sample was extracted in a flat bottom flask with 2.5 liters hexane by maceration for 24 hours with intermittent shaking. The sample mixture was filtered with muslin cloth and with vacuum pump filtration. The filtrate was concentrated using rotary vacuum evaporator at $40^{\circ} \mathrm{C}$. The concentrated/dried extract was collected into a pre-weighed sterile universal bottle and stored until required for microbiological assay. This process was repeated using chloroform, ethyl acetate and methanol. The percentage extract yields of the plant samples were calculated as:

\footnotetext{
Percentage extract yield $(\%)=$ Weight of dried extract $\times 100$ [8].

Weight of dried powder
}

The purity of the isolate (Streptococcus pyogenes) was ascertained by plating on different selective agar media before carrying out biochemical tests. The purity of the test bacteria was confirmed by sub-culturing into nutrient broth and incubating at $37^{\circ} \mathrm{C}$ for 18 
hours. The 18-hour broth culture was streaked unto sterile nutrient agar plates and incubated at $37^{\circ} \mathrm{C}$ for 18 hours. The colonies were observed under the light microscope after simple Gram staining. Isolation of specific bacteria was done by streaking on selective media. A loopful of inoculum from the 18-hour broth culture was streaked on selective agar and incubated at $37^{\circ} \mathrm{C}$ for 18 hours. The cultural characteristics of the untyped Streptococcus pyogenes was checked on blood agar. The cultural characteristics and biochemical tests were observed and compared to standard references [9].

Standardization of inocula: The Clinical Laboratory Standard Institute (CLSI, 2000 a) as described by Adeshina, Onaolapo, Ehinmidu \& Odama (2010) was adopted to standardize the inoculum [5, 10]. Eighteenhour broth culture of each test organism was standardized by gradually adding normal saline to compare its turbidity to McFarland standard of 0.5 which is approximately $1.0 \mathrm{x}$ $10^{6} \mathrm{cfu} / \mathrm{ml}$. The turbidity of the cell culture was matched with that of the $0.5 \mathrm{McFarland}$ standard by holding the mixture and the standard in front of light against a white background with contrasting black lines through visual comparison with its density by the addition of normal saline.

Antibacterial susceptibility test: The agarwell diffusion method of CLSI [12] as adopted [14] was employed to screen the root extracts for antibacterial activity. Overnight broth cultures were diluted appropriately using the McFarland scale (0.5 McFarland which is approximately $\left.1.0 \times 10^{6} \mathrm{cfu} / \mathrm{ml}\right)$. The molten sterile Mueller-Hinton agar $(20 \mathrm{ml})$ was poured into a sterile Petri dish and allowed to set. The sterile MHA plates were flooded with $1.0 \mathrm{ml}$ of the standardized culture of each test organism and the excess drained off. Wells of $6 \mathrm{~mm}$ diameter were bored into the inoculated plates using sterile a cork borer $(6 \mathrm{~mm})$. One drop of the molten agar was used to seal the bottom of the bored hole so that the extract would not seep beneath the agar. Five grams (5 $\mathrm{g})$ of each root extract was dissolved in $10 \mathrm{ml}$ of $10 \%$ dimethyl sulfoxide (DMSO) solution in water to obtain a stock solution of 500 $\mathrm{mg} / \mathrm{ml}$ concentration. Using micropipette, two hundred microliters $(200 \mu \mathrm{l})$ of the root extract stock concentration was dispensed into each agar-well. Standard antibiotic (ofloxacin) was used as positive control while sterile distilled water and 10\% DMSO served as negative controls. These were allowed to diffuse into the agar at room temperature $\left(25-28^{\circ} \mathrm{C}\right)$ for one hour before incubation at $37^{\circ} \mathrm{C}$ for 24 hours. The experiment was carried out in duplicates and the inhibition zones diameter were measured to the nearest millimeter ( $\mathrm{mm}$ ) and mean and standard deviation of the duplicates were recorded

Determination of minimum inhibitory concentration (MIC): The agar well dilution method (modified) according to CLSI [13] as adapted by Campana [11] was employed to determine the minimum inhibitory concentration of active root extracts. From a stock concentration of $4 \mathrm{~g} / 20 \mathrm{ml}$, different concentrations of both aqueous and solvent extracts $(200,100,50,25,12.50,6.25,3.12$ and $1.56 \mathrm{mg} / \mathrm{ml}$ ) were prepared in $10 \%$ dimethyl sulfoxide (DMSO). $10 \mathrm{ml}$ of each of the prepared concentrations of the root extract was mixed with $10 \mathrm{ml}$ of double strength (doubling the agar manufacturer recommended weight of the agar to be dissolved in the same volume water) molten Mueller-Hinton agar at $45{ }^{\circ} \mathrm{C}$ and poured into Petri-plates aseptically and allowed to solidify. The mixture gave a final various extract concentration as 100,50 , $25,12.5,6.25,3.125,1.56$ and $0.78 \mathrm{mg} / \mathrm{ml}$ for the study. After setting, sterile paper discs (6 $\mathrm{mm}$ ) were placed equidistance to the surface of the set agar containing the various extract concentrations. Ten microliters $(10 \mu \mathrm{l})$ of each standardized organism/inoculum $\left(10^{6} \mathrm{cfu} / \mathrm{ml}\right)$ was then spot-inoculated on each disc and allowed to diffuse for 30 minutes before incubating at $37{ }^{\circ} \mathrm{C}$ for 18 - 24 hours. Growth 
control was prepared by inoculating $10 \mu \mathrm{l}$ of each culture suspensions on $15 \mathrm{ml}$ MHA medium without any extract or solvent (drugfree medium). Solvent control was prepared by pouring $1 \mathrm{ml}$ of $10 \%$ DMSO to $14 \mathrm{ml}$ of MHA medium followed by seeding of cultures. The first lowest concentration that showed no visible growth of the inoculated test organism was recorded as the MIC of the extract for the test organism after overnight incubation.

Determination of minimum bactericidal concentration (MBC). All inoculated paper discs showing no visible growth from MIC determination were aseptically transferred to 5 $\mathrm{ml}$ of sterile Nutrient broth containing $5 \%$ Yeast extract and $3 \%$ Tween 80 to neutralize the effect of the extracts and incubated for another 18 hours at $37^{\circ} \mathrm{C}$. The discs from the lowest concentration of each extract that showed no visible growth (cloudiness) was taken as the MBC of each plant extract against the test organism.

Determination of time-kill kinetics
antibacterial study of Adenodolichos
paniculatus chloroform root extract against
the test bacteria. The method of $[15]$ (modified) as adapted by [8] was employed to determine the rate of kill of each test bacteria by the chloroform root extract of $A$. paniculatus. One milliliter $(1.0 \mathrm{ml})$ of standardized culture $\left(10^{6} \mathrm{cfu} / \mathrm{ml}\right)$ of $S$. pyogenes, $S$. aureus and $P$. aeruginosa was separately added to $9.0 \mathrm{ml}$ of different MIC concentrations (MIC \& $2 \mathrm{x}$ MIC) of the chloroform root extract $(1.56,6.25,25$ and $3.12,12.5$ and $50 \mathrm{mg} / \mathrm{ml}$ respectively in a sterile universal bottle such that the final test suspension contained approximately $10^{6} \mathrm{cfu} / \mathrm{ml}$ of each test organism. The suspensions were kept in water bath at $37{ }^{\circ} \mathrm{C}$. At pre-determined time intervals of $0,30,60,120,180,240,720$ and 960 minutes, $1 \mathrm{ml}$ of the admixture was withdrawn and diluted ten-fold with $9 \mathrm{ml}$ sterile normal saline containing $3 \%$ Tween 80 , $5 \%$ yeast extract and $0.3 \%$ egg lecithin. Exactly $0.1 \mathrm{ml}$ of each dilution was aseptically plated out in duplicates using pour-plate method for viable counts after 24 hours incubation at $37{ }^{\circ} \mathrm{C}$. Colony counts were plotted against time intervals on a semi-log graphing paper to obtain the killing curve for each selected fixed concentration of the various extracts. The percentage reduction and log reduction from initial microbial population for each time point was calculated to express the change (reduction or increase) of the microbial population relative to a starting inoculum.

The change was determined as follows:

$\%$ Reduction $=$

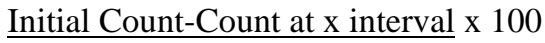
Initial count

The log reduction was calculated as follows:

$\log _{10}($ initial count $)-\log _{10}(\mathrm{x}$ time interval $)=\log _{10}$ reduction [16 \& 17]

\section{RESULTS}

The result of the study as presented in table 1 showed that the chloroform root extract exhibited in vitro antibacterial activity on three of the four selected test bacteria at a concentration of $100 \mathrm{mg} / \mathrm{ml}$. The chloroform root extract proved to be the most active and exhibited antibacterial activity against three $(S$. aureus, $S$. pyogenes and $P$. aeruginosa) of the four bacteria tested with inhibition zone diameters ranging from 14.75 to $25.00 \mathrm{~mm}$. The largest IZD $(25.00 \mathrm{~mm})$ was produced by chloroform root extract against $S$. pyogenes, $S$. aureus $(21 \mathrm{~mm})$ and $P$. aeruginosa $(14.75$ $\mathrm{mm})$. The chloroform root extract showed no activity against $E$. coli. The minimum inhibitory concentration of the extract against $S$. pyogenes, $S$. aureus and $P$. aeruginosa were $1.56,6.25$ and $25.00 \mathrm{mg} / \mathrm{ml}$ respectively while the minimum bactericidal concentrations for the three test bacteria was $3.12,12.50$ and $50.00 \mathrm{mg} / \mathrm{ml}$.

The percentage and the log reductions from the initial microbial population for each time point were calculated to express the change (reduction or increase) of the microbial 
population relative to a starting inoculum. Log of death/survival rate of each test bacteria on exposure to different concentration (MIC and 2xMIC) of $A$. paniculatus chloroform root extract was plotted as presented in Figures 1 and 2. Both Figures depicted the time-kill kinetics assay of the extract against the three test bacteria ( $S$. aureus, $S$. pyogenes and $P$. aeruginosa).

The results indicated that the extract exhibited a significant reduction in the viable cell count of the test bacteria after 30 minutes at the MIC concentrations. The reduction of viable cells $(\log \mathrm{cfu} / \mathrm{ml})$ of the test bacteria were $0.11 \log _{10}, 0.9 \log _{10}$ and $0.9 \log _{10}$ for
Streptococcus pyogenes, Staphylococcus aureus and Pseudomonas aeruginosa respectively. This translated to $20.83,16.36$ and $15.00 \%$ respectively. When contact time was increased to 60 minutes at the same concentration, the log reduction in viable cell population were $2.1 \log _{10}, 1.8 \log _{10}$ and $1.6 \log _{10}$ respectively. This reduction in viable cells corresponds to $33.33,30.18$ and $31.14 \%$ respectively. However, the extract exhibited bactericidal effect/activity, reducing the log $\mathrm{cfu} / \mathrm{ml}$ by greater than 3 logs (6.65log), (3.1log) and (3.2log) as from 240, 300 and 720 min exposure when the cells death were increased to $79.17,72.72$ and $75 \%$.

Table 1: Antibacterial Activities of Root Extracts against Test Organisms

\begin{tabular}{|c|c|c|c|c|}
\hline $\begin{array}{l}\text { Extract } \\
\text { type/concentration }\end{array}$ & Test Organisms & $\begin{array}{l}\text { Zone of Inhibition } \\
(\mathrm{mm})\end{array}$ & M.I.C (mg/ml) & $\begin{array}{l}\text { M.B.C } \\
(\mathrm{mg} / \mathrm{ml})\end{array}$ \\
\hline \multirow{4}{*}{$\begin{array}{l}\text { N-Hexane Extract } \\
(100 \mathrm{mg} / \mathrm{ml})\end{array}$} & Streptococcus pyogenes & NA & NA & NA \\
\hline & Staphylococcus aureus & NA & NA & NA \\
\hline & Pseudomonas aeruginosa & NA & NA & NA \\
\hline & Escherichia coli & NA & NA & NA \\
\hline \multirow{4}{*}{$\begin{array}{l}\text { Chloroform Extract } \\
100 \mathrm{mg} / \mathrm{ml})^{*}\end{array}$} & Streptococcus pyogenes & $25.00 \pm 0.00$ & 1.56 & 3.12 \\
\hline & Staphylococcus aureus & $21.00 \pm 0.00$ & 6.25 & 12.50 \\
\hline & Pseudomonas aeruginosa & $14.75 \pm 0.35$ & 25.00 & 50.00 \\
\hline & Escherichia coli & NA & NA & NA \\
\hline \multirow{4}{*}{$\begin{array}{l}\text { Ethyl acetate Extract } \\
(100 \mathrm{mg} / \mathrm{ml})\end{array}$} & Streptococcus pyogenes & $18.50 \pm 0.70$ & 12.50 & 25.00 \\
\hline & Staphylococcus aureus & $13.00 \pm 0.00$ & 12.50 & 25.00 \\
\hline & Pseudomonas aeruginosa & NA & NA & NA \\
\hline & E. coli & NA & NA & NA \\
\hline \multirow{4}{*}{$\begin{array}{l}\text { Methanol Extract } \\
(100 \mathrm{mg} / \mathrm{ml})\end{array}$} & Streptococcus pyogenes & $14.00 \pm 0.00$ & 12.50 & 25.00 \\
\hline & Staphylococcus aureus & $13.50 \pm 0.35$ & 25.00 & 50.00 \\
\hline & Pseudomonas aeruginosa & NA & NA & NA \\
\hline & Escherichia coli & NA & & \\
\hline \multirow{4}{*}{$\begin{array}{l}\text { Water Extract } \\
(100 \mathrm{mg} / \mathrm{ml})\end{array}$} & Streptococcus pyogenes & $17.75 \pm 0.35$ & 12.50 & 25.00 \\
\hline & Staphylococcus aureus & $13.75 \pm 0.35$ & 25.00 & 50.00 \\
\hline & Pseudomonas aeruginosa & NA & NA & NA \\
\hline & Escherichia coli & NA & NA & NA \\
\hline \multirow{4}{*}{$\begin{array}{l}\text { Control (Ofloxacin } \\
(5 \mu \mathrm{g} / \mathrm{disc})\end{array}$} & Streptococcus pyogenes & $26.00 \pm 0.00$ & 2.5 & 5 \\
\hline & Staphylococcus aureus & $21.00 \pm 0.00$ & 5 & 10 \\
\hline & Pseudomonas aeruginosa & $15.75 \pm 0.35$ & 10 & 20 \\
\hline & Escherichia coli & $27.75 \pm 0.35$ & 5 & 10 \\
\hline
\end{tabular}

$\mathrm{NA}=$ No activity $\mathrm{MIC}=$ Minimum Inhibitory Concentration $\mathrm{MBC}=$ Minimum Bactericidal Concentration 


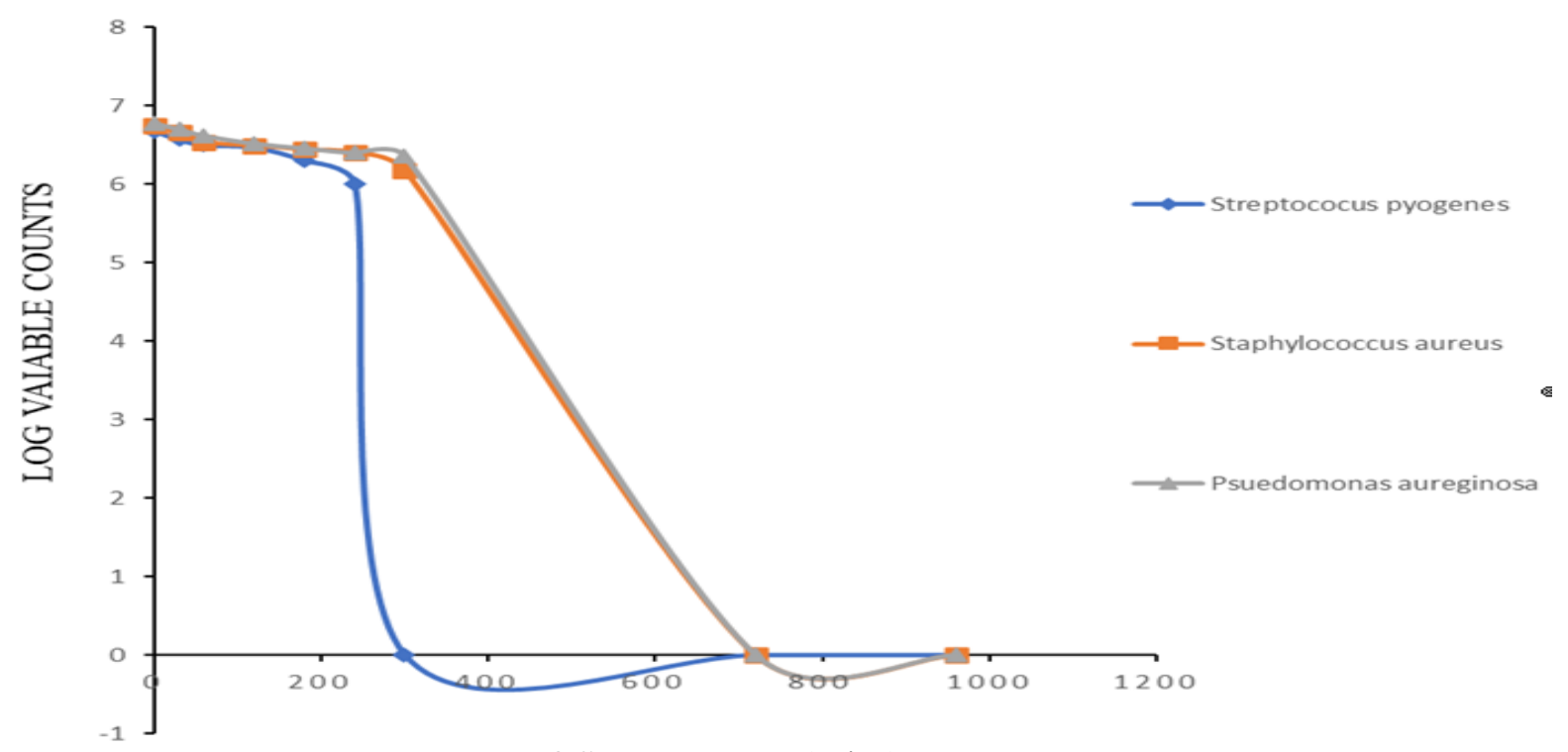

EXPOSURE TIME (min.)

Fig. 1. Survival curve of test bacteria exposed to chloroform root extracts of Adenodolichos

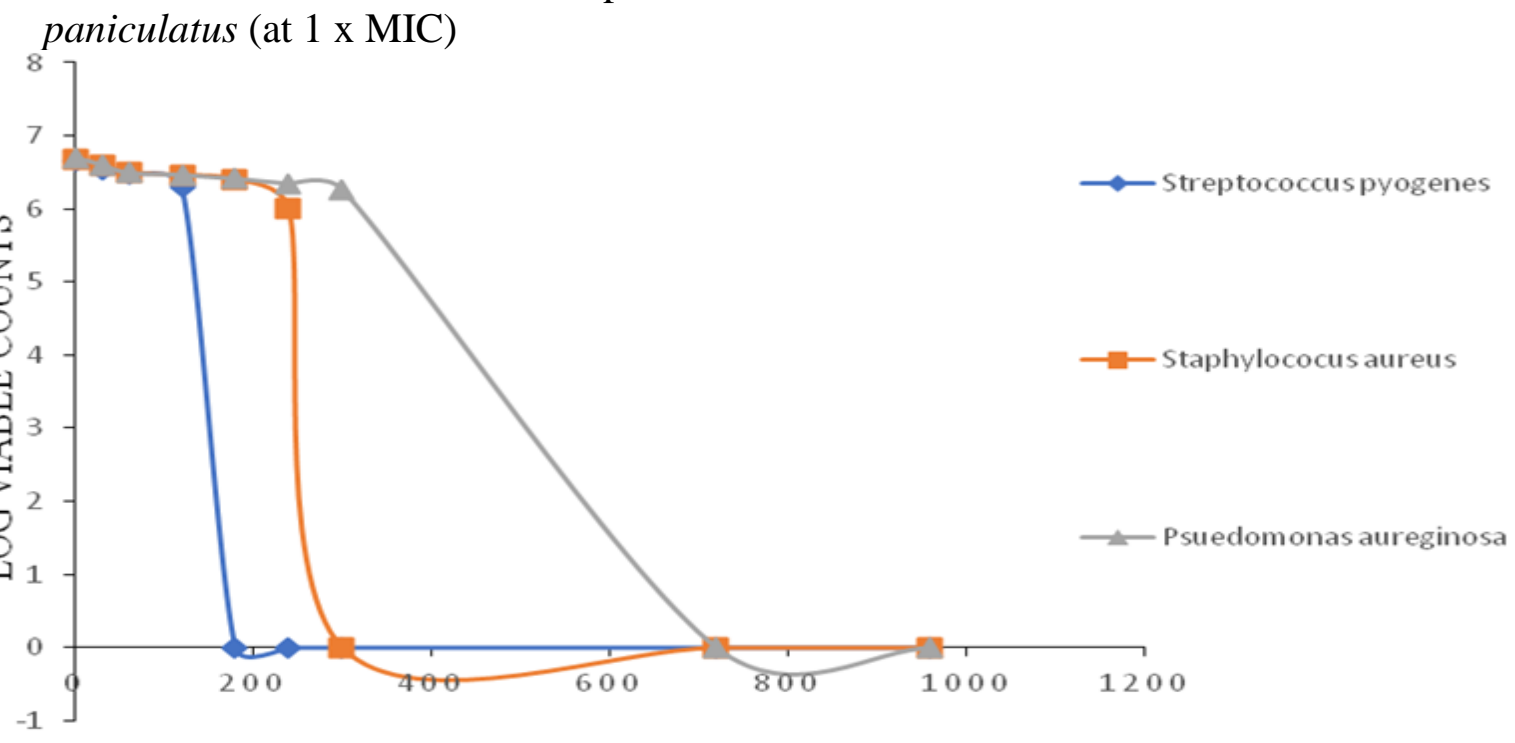

EXPOSURE TIME (min.)

Fig.2. Survival curve of test bacteria exposed to chloroform root extracts of Adenodolichos Paniculatus against (at 2xMIC)

Finally a $100 \%$ complete killed effect was achieved at 300, 720 and 960 minutes exposure for $S$. pyogenes, $S$. aureus and $P$. aeruginosa. The extract exhibited both time-dependent and concentration-dependent killing profiles with $S$. pyogenes as the fasted killed at both concentrations (MIC and 2x MIC) followed by $S$. aureus and finally $P$. aeruginosa.

\section{DISCUSSION}

The result of the study showed that the chloroform root extract exhibited in vitro antibacterial activity on three of the four selected test bacteria at a concentration of 100 $\mathrm{mg} / \mathrm{ml}$. This means none of the compounds extracted by chloroform have activity against E. coli. The antibacterial susceptibility test results of the extract compared favorably with 
the positive control antibiotic as the difference between the inhibition zone diameter of each the test bacteria between that of the chloroform root extract and the control drug was not statistically significant $(\mathrm{P}>0.05)$.

Not many studies have been reported on the antibacterial properties of this plant against some test bacteria. However, it has been reported from the study of antimicrobial activity of ethanolic and aqueous extracts of Caesalpinia pulcherrima (same family with Adenodolichos paniculatus) has demonstrated antibacterial activities on Staphylococcus aureus and Escherichia coli [18]. Also, it has been reported from the study of antimicrobial activity of ethanolic and aqueous thorns extracts of Mimosa pudica (same family with Adenodolichos paniculatus) has demonstrated antibacterial activities on Pseudomonas aeruginosa [19]

Time-kill kinetics antibacterial study has been used to investigate numerous antimicrobial agents and they are also often used as the basis for in-vitro investigations for pharmacodynamic drug interaction [20]. The time kill kinetic antibacterial assay of the root extract of $A$. paniculatus gave variable kinetics against susceptible bacteria tested. For the first time, efforts were made in this study to explore time-kill kinetics of antibacterial activity of this plant. The extract demonstrated both bacteriostatic and bactericidal effects as it shows a concentration-dependent effect. A significant decrease in the population of the test bacteria with increased contact time was observed.

A complete elimination of $S$. pyogenes, $S$. aureus and $P$. aeruginosa was achieved as from $300 \mathrm{mins}(5 \mathrm{~h})$ at MIC $(1.56 \mathrm{mg} / \mathrm{ml}), 720$ mins $(12 \mathrm{~h})$ at $6.25 \mathrm{mg} / \mathrm{ml}$ and 960 minutes $(16$ h) at $25.00 \mathrm{mg} / \mathrm{ml}$ of exposure respectively and from $180 \mathrm{mins}(3 \mathrm{~h})$ at $2 \mathrm{x} \mathrm{MIC}(3.12 \mathrm{mg} / \mathrm{ml})$, $300 \mathrm{mins}(5 \mathrm{~h})$ at $25.00 \mathrm{mg} / \mathrm{ml}$ and from 720 mins $(12 \mathrm{~h})$ at $50.00 \mathrm{mg} / \mathrm{ml}$ exposure respectively. These results provided quantitative information on dose-response rate and time-dependent concentrations required to make a significant decrease in the initial bacterial inoculum. These findings may be considered initial steps of in vitro pharmacodynamics of antibacterial activity of A. paniculatus. $S$. pyogenes is the most susceptible bacteria that was inhibited and eliminated shortly after exposure. At higher concentration and longer duration of contact time, more bacteria were killed. As the graph depicted, the test bacteria were affected, with gradual decrease in cell population after which there was a total kill. This indicated that the bactericidal activity of the chloroform root extract was both concentration and time dependent with time being more influential as earlier observed [21].

After contact time of 240, 300 and 720 mins at MIC there were virtually no surviving cells of all the test bacteria ( $S$. pyogenes, $S$. aureus and $P$. aeruginosa respectively). It was observed in the study that the rate of killing was higher when the extract concentration was increased to 2x MIC. After contact time of 180, 240 and 300 mins at $2 \mathrm{x} \mathrm{MIC,}$ there were virtually no surviving cells of all the test bacteria ( $S$. pyogenes, $S$. aureus and $P$. aeruginosa respectively). The result obtained in this study corroborates the previous study [20] in the time-kill study of time kill-kinetics antibacterial study of Acacia nilotica that the time-kill was time and concentration dependent. It also corroborates with a previous study in the invitro antibacterial time-kill studies of leaves extracts of Helichrysum longifolium that the time-kill was both concentration and time dependent [22]

In conclusion, the findings in this study provides scientific support for its use traditionally. Further study through high through put techniques could yield potential lead molecules in bio-prospecting for phytomedicine. 


\section{REFERENCES}

1. Abdulsalam I.A, Ehinmidu, J.O and Igbadi E.O. (2013). Evaluation of Antibacterial Properties, Acute Toxicity and Immuno-stimulatory Potential of Scoparia dulcis. Nigerian Journal of Biotechnology, (26):21-25.

2. Burkill, H. M. The Useful Plants of Tropical West Africa, Families A D Royal Botanical Garden, Kew, 1985a, 1-254

3. Burkill, H. M. (Ed.) The Useful Plants of West Tropical Africa: Families A D. Kew, Royal Botanic Gardens, 1985b, 1-319

4. Hutchinson, J. and Dalziel, J. M. Caesalpiniaceae, Mimosaceae and Papilionaceae. Flora of West Tropical Africa, 1 1958; (2):439-587

5. Adeshina, G., O., Onaolapo, J. A., Ehinmidu, J. O. and Odama, L. E. (2010). Phytochemical and Antimicrobial Studies on the Ethyl acetate Extract of Alchornea cordifolia leaf found in Abuja-Nigeria. Journal of Medicinal Plants Resources, 4(8):649658.

6. Isyaku I, Bello A.I, Ndukwe G.I and Kizito I.G (2020). Isolation and Characterization of Nonanoic Acid from Ethyl Acetate Extract of Adenodolichos paniculatus. Communication in Physical Sciences, 2020, 5(3):337-342

7. Banu K.S and Catherine, L, (2015). General Techniques Involved in Phytochemical Analysis. International Journal of Advanced Research in Chemical Sciences 2 (4): 25-32

8. Ali A.I, Ehinmidu J.O and Ibrahim Y.K.E. (2011). Preliminary Phytochemical Screening and Antimicrobial Activities of some Medicinal Plants used in Ebiraland. Bayero Journal of Pure and Applied Sciences, 4(1):10-16.

9. Murray, P. R., Baron, E. J., Jorgensen, J. H., Landry, M. L. and Pfaller, M. A. (ed.) (2007). Manual of Clinical Microbiology, 9th Edition. ASM Press, Washington, D. C.

10. Clinical and Laboratory Standards Institute. (2000 a) Methods for dilution antimicrobial susceptibility tests for a bacterial that grow aerobically, approved standard. In M7-A7, Wayne, Pennsylvania, USA: CLSI.

11. Campana et al., (2014). Comparison of M.I.C.E and Etest with CLSI agar dilution for Antimicrobial susceptibility testing against oxacillin-resistant Staphylococcus spp. PLosONE,9(4).doi.org/10.1371/journal.pone.0094 $\underline{627 .}$
12. Clinical Laboratory Standards Institute (CLSI) (2009). Methods for dilution antimicrobial susceptibility test for bacteria that grow aerobically-approved guideline M7-A8. PA, USA.

13. Clinical Laboratory Standards Institute (CLSI) (2012). Performance standards for antimicrobial susceptibility testing: twenty second Information Supplement (M100-S22). PA, USA.

14. Sedighinia et al., (2012). Antibacterial Activity of Glycyrrhiza glabra against Oral pathogens: an InVitro Study. Avicenna Journal of phytomedicine, 2(3), 118-24.

15. Odeyemi O, Oluduro A., O and David O., M. (2014). Evaluation of Antimicrobial Activities of Albizia zygia DC Leaf Extracts against some Clinically important Pathogens. Journal of Natural Sciences Research, 4(19), 98-106

16. ASTM, (2008). ASTM Standard Guide for Assessment of Antimicrobial Activity Using a Time-Kill Procedure. Method E2315-16

17. Elloff, J.N. (1998). Which Extractant should be used for Screening and Isolation of Antibacterial Components from plants? Journal of Ethnopharmacology, Lagos. 60:1-6

18. Dhaked P.S, Kshirsagar S.N and Sakara (2011). Antimicrobial Activity of Ethanolic and Aqueous Extracts of Caesalpinia pulcherrima flowers. International Journal of Pharmaceutical Sciences and Research 2(10):2643-2646.

19. Lakshmibai R and Amirtham D (2018). Antimicrobial Activity of Mimosa pudica thorns Ethanolic and Aqueous Extracts. International Journal of Pharmacy 9(6):202-206

20. Oladosu P, Isu N.R, Ibrahim K, Okolo $P$ and Oladepo D.K. (2013). Time Kill-Kinetics Antibacterial Study of Acacia nilotica. African Journal of Microbiology Research, 7 (46):52485252.

21. Ogunwonyi I.H, Ntsikelelo M, Leonard M, Elvis N, Ezekiel G, David A.A, Ademola O.O and Anthony I.O. (2010). In vitro Time-kill Studies of Antibacterial Agents from Putative Marine Streptomyces species Isolated from the Nahoon beach, South Africa. South African Journal of Pharmaceutical Pharmacology, 4 (12):908-916.

22. Aiyegoro O.A, Afolayan A.J and Okoh A.I (2009). Invitro Antibacterial Time-kill Studies of Leaves Extracts of Helichrysum longifolium. Journal of Medicinal Plants Research 3(6), pp.462-467. 